\title{
Monovalent Alkali Cations: Simple and Eco-Friendly Stabilizers for Surfactant-Free Precious Metal Nanoparticle Colloids
}

Quinson, Jonathan; Bucher, Jan; Simonsen, Søren B.; Kuhn, Luise Theil; Kunz, Sebastian; Arenz, Matthias

\section{Published in:}

ACS Sustainable Chemistry and Engineering

Link to article, DOI:

10.1021/acssuschemeng.9b00681

Publication date:

2019

Document Version

Peer reviewed version

Link back to DTU Orbit

Citation (APA):

Quinson, J., Bucher, J., Simonsen, S. B., Kuhn, L. T., Kunz, S., \& Arenz, M. (2019). Monovalent Alkali Cations: Simple and Eco-Friendly Stabilizers for Surfactant-Free Precious Metal Nanoparticle Colloids. ACS Sustainable Chemistry and Engineering, 7(16), 13680-13686. https://doi.org/10.1021/acssuschemeng.9b00681

\section{General rights}

Copyright and moral rights for the publications made accessible in the public portal are retained by the authors and/or other copyright owners and it is a condition of accessing publications that users recognise and abide by the legal requirements associated with these rights.

- Users may download and print one copy of any publication from the public portal for the purpose of private study or research.

- You may not further distribute the material or use it for any profit-making activity or commercial gain

- You may freely distribute the URL identifying the publication in the public portal 


\section{Monovalent alkali cations: simple and eco-friendly}

\section{stabilizers for surfactant-free precious metal}

\section{nanoparticle colloids}

Jonathan Quinson, ${ }^{* \cdot a}$ Jan Bucher, ${ }^{b}$ Søren B. Simonsen, ${ }^{c}$ Luise Theil Kuhn, ${ }^{c}$ Sebastian Kunz ${ }^{d,{ }^{c}}$ and Matthias Arenz ${ }^{*}, b$

${ }^{a}$ Chemistry Department, University of Copenhagen, Universitetsparken 5, 2100 Copenhagen $\varnothing$, Denmark

${ }^{b}$ Department of Chemistry and Biochemistry, University of Bern, Freiestrasse 3 CH-3012 Bern, Switzerland.

${ }^{\mathrm{c}}$ Imaging and Structural Analysis, Department of Energy Conversion and Storage, Technical University of Denmark, Frederiksborgvej 399, 4000 Roskilde, Denmark

${ }^{\mathrm{d}}$ Institute for Applied and Physical Chemistry, University of Bremen, Leobenerstraße 28359

Bremen, Germany

Corresponding authors: ～jonathan.quinson@chem.ku.dk; 004550288974

matthias.arenz@dcb.unibe.ch 
DOI: 10.1021/acssuschemeng.9b00681

\title{
KEYWORDS
}

Co4Cat technology; Colloids; Nanoparticles; Cations; Alkali; Surfactant-free

\begin{abstract}
The Co4Cat approach is a surfactant-free industry-relevant method to synthesize precious metal nanoparticles with enhanced catalytic properties. Colloidal nanoparticles are obtained by reduction of a metal salt in a mono-alcohol such as methanol in presence of a base. As opposed to alternative surfactant-free syntheses, in the Co4Cat approach the nature of the alkali cations used strongly influences the most suitable strategy to achieve different nanoparticle size, to best process and stabilize surfactant-free platinum nanoparticles. The rational selection of the base needed in the Co4Cat process is here detailed. Monovalent alkali cations stabilize the assynthesized and re-dispersed nanoparticles in mono-alcohols and aqueous solvents with the decreasing order of efficiency: $\mathrm{Li}^{+}>\mathrm{Na}^{+}>\mathrm{K}^{+} \approx \mathrm{Cs}^{+}$which correlates with the decreasing hydration energy of the cation. $\mathrm{Li}^{+}$and $\mathrm{Na}^{+}$cations are shown to serve as simple, eco-friendly and efficient stabilizers for surfactant-free platinum nanoparticle colloids.
\end{abstract}




\section{INTRODUCTION}

Controlling the synthesis of nanomaterials and in particular colloidal dispersions of precious metal nanoparticles (NPs) is essential to develop novel tailored catalysts for energy conversion, ${ }^{1-}$ ${ }^{3}$ chemical production ${ }^{4}$ or medical applications. ${ }^{5}$ Preparing stable colloidal NP dispersions is key to process the nanomaterials more efficiently, at lower cost, with lower impact on the environment, and to optimize the use of the precious metals. The stabilization of colloidal dispersions is commonly achieved using additives like surfactants, ${ }^{6-11}$ which are unfortunately detrimental for most applications and require costly and/or hazardous removal steps. ${ }^{12-15}$ Therefore, surfactant-free syntheses are preferred in sustainable productions. ${ }^{16,17}$

Popular methods to prepare surfactant-free and 'unprotected' metal NPs are solution based syntheses where the particle formation is triggered either by conventional heating or laser ablation. ${ }^{18-20}$ In particular, the synthesis of precious metal NPs can be performed using the polyol synthesis ${ }^{11,21-23}$ where the high viscosity of the solvent plays a role in the stabilization of the NPs. ${ }^{21,24} \mathrm{CO}$ and $\mathrm{OH} / \mathrm{OH}^{-}$groups also account for the stabilization of the $\mathrm{NPs}^{25}$ and their water dispersibility. ${ }^{26}$ Despite monovalent alkali cations being involved in a range of syntheses like the polyol process, their role in the stabilization and re-dispersion properties of precious metal NPs is not often addressed, nor exploited. To the best of our knowledge until now, the influence of monovalent alkali cations in precious metal NP syntheses has been overshadowed by three popular approaches to stabilize NPs in wet-chemistry routes: the use of polymers, of anionic species and/or viscous solvents.

Here we stress and discuss the importance of monovalent alkali cations in the synthesis, on the colloidal stability, and on the re-dispersion properties of surfactant-free platinum (Pt) NPs obtained by the 'Co4Cat' process. ${ }^{27,28}$ The Co4Cat process has been introduced as a novel, 
industry-relevant synthesis approach that bears economic and ecological advantages over the state-of-the-art to obtain stable colloidal nanoparticle suspensions due to its simplicity, the avoidance of harmful chemicals and because it leads to highly active catalysts, thus optimizing the use of precious metal resources. In the Co4Cat process a metal precursor like $\mathrm{H}_{2} \mathrm{PtCl}_{6}$ is reduced from the $\mathrm{Pt}(\mathrm{IV})$ oxidation state to $\mathrm{Pt}(\mathrm{II})$ and then $\mathrm{Pt}(0)$ nanoparticles at low temperature (e.g. $<80^{\circ} \mathrm{C}$ ) in an alkaline mono-alcohol like methanol without polymers or surfactants, while the solvent gets oxidized. ${ }^{28,}{ }^{29}$ Size control in the range 2-6 $\mathrm{nm}$ was achieved by adding substantial amounts of water and the NP size increases with the water content. The latter observation can be ascribed to the lower concentration of the reducing agent (e.g. methanol) leading to a reduced reaction rate, possibly affecting the seed formation/particle growth ratio. Alternatively, it may also be related to the decreased formation of $\mathrm{CO}$ groups by oxidation of the alcohol leading to lower stabilization of the nanoparticles. ${ }^{28}$ The exact mechanism is difficult to prove and was not investigated further in this study. Note, that even the pure alcohol used in the synthesis contains some water; no dried solvents were used since they are not needed to achieve small NP sizes.

Instead here we focused on the influence of alkali cations in the synthesis and stabilization of the colloids. For this, different alkali cations were tested in the synthesis procedure. Noncovalent interactions between alkali metals and adsorbed $\mathrm{OH}$ species on $\mathrm{Pt}$ are known to decrease with the hydration energy of the cation in the order $\mathrm{Li}^{+}>>\mathrm{Na}^{+}>\mathrm{K}^{+}>\mathrm{Cs}^{+}$. Their role in electrochemical reactions is less studied (as compared to the role of anions ${ }^{7,19}$ ), however, it has been reported that the electrochemical activity of Pt in alkaline electrolytes is governed by such non-covalent interactions. ${ }^{30}$ This electrochemical knowledge is here transferred to control various steps in the "life cycle" of Pt NPs: from strategic synthesis choices, all the way down to 
re-dispersion - so ultimately applications - of colloidal nanoparticles in green solvents like methanol and water. ${ }^{31}$

\section{EXPERIMENTAL SECTION}

Chemicals. All chemicals were used as received: $\mathrm{H}_{2} \mathrm{PtCl}_{6} \cdot 6 \mathrm{H}_{2} \mathrm{O}\left(99.9 \%\right.$ Alfa Aesar); $\mathrm{K}_{2} \mathrm{PtCl}_{6}$ (Alfa Aesar); $\mathrm{K}_{2} \mathrm{PtCl}_{4}$ (99.9\% Alfa Aesar); $\mathrm{LiOH}$ (anyhdrous 98 \%, Alfa Aesar); $\mathrm{NaOH}(98 \%$, Alfa Aesar); $\mathrm{KOH}\left(\mathrm{KOH} . \mathrm{xH}_{2} \mathrm{O}, \geq 99.995 \%\right.$, Fluka); $\mathrm{CsOH}$ (99.95\%, Aldrich); ethylene glycol (99+\%, Sigma-Aldrich); methanol ( $\geq 99.8 \%$, Sigma-Aldrich); ethanol (99.9\%, Kemetyl); water (Milli-Q, Millipore, resistivity $>18.2 \mathrm{M} \Omega \cdot \mathrm{cm}$, total organic carbon $(\mathrm{TOC})<5 \mathrm{ppb}) ; \mathrm{NaHPO}_{4}(\geq$ $99.0 \%$, Sigma); $\mathrm{Na}_{2} \mathrm{PO}_{4}\left(\geq 99.0 \%\right.$, Sigma); $\mathrm{KHPO}_{4}(\geq 99.0 \%$, Sigma $) ; \mathrm{K}_{2} \mathrm{PO}_{4}(\geq 99.0 \%$,

Sigma); carbon support (Vulcan XC72R, Cabot Corporation, BET area: $235 \mathrm{~m}^{2} \mathrm{~g}^{-1}$ ); $\mathrm{NaCl}$ (ReagentPlus ${ }^{\circledR}$, Sigma-Aldrich, $\left.\geq 99.0 \%\right) ; \mathrm{KCl}$ (EMSURE®.for analysis), $\mathrm{HNO}_{3}(65 \%$, Suprapur®, EMD Millipore, Merck KGaA), HCl (Suprapur®, EMD Millipore, Merck KGaA).

\section{Synthetic procedures.}

Traces of water (from the solvent, the precursor of the base used) were reported to be key for the reduction of precious metals in the polyol synthesis ${ }^{32}$ and no extra effort was made to work in dry mono-alcohols solvents.

\section{Synthesis of Pt NPs in alkaline mono-alcohols.}

The general synthesis consists in dispersing $\mathrm{H}_{2} \mathrm{PtCl}_{6} \cdot 6 \mathrm{H}_{2} \mathrm{O}(0.5$ to $2.5 \mathrm{mM}$ ), alternatively $\mathrm{K}_{2} \mathrm{PtCl}_{6}$, in an alkaline solution of $\mathrm{LiOH}, \mathrm{NaOH}$ or $\mathrm{KOH}$ with or without added water (as indicated). The stock solution of base used to prepare the reaction mixture is prepared at $57 \mathrm{mM}$ of base. The solubility of $\mathrm{LiOH}$ is slightly lower than $\mathrm{NaOH}$ or $\mathrm{KOH}$ in methanol but still high enough to dissolve the salt completely if enough time is given. The stock solution of $\mathrm{H}_{2} \mathrm{PtCl}_{6}$ is 
prepared at $20 \mathrm{mM}$. The base/Pt molar ratio was adjusted to 20 in the final reaction mixture if not indicated otherwise. The reaction mixture is obtained by mixing the two previously described stock solutions $\left(\mathrm{H}_{2} \mathrm{PtCl}_{6}\right.$ and base) in the desired ratios. The reaction mixture (typically 8 to 80 $\mathrm{mL}$ ) is placed in a reflux set up and heated up with a micro-wave reactor (CEM Discover SP, $100 \mathrm{~W}$ ). While the solution is irradiated a flow of $\mathrm{N}_{2}$ is passed on the outside of the vessel to cool it down, otherwise the temperature raises too quickly. No stirring is performed.

For the comparison shown in Figure 1, $2.5 \mathrm{mM} \mathrm{H}_{2} \mathrm{PtCl}_{6}$ in alkaline methanol or $75 \%$ water and $25 \%$ methanol (as indicated) was used. The NPs were obtained under reflux conditions with a microwave reactor continuously operated at $100 \mathrm{~W}$ for an additional 45 minutes after the reaction mixture turned dark. The volume of the reaction mixture was $8 \mathrm{~mL}$.

For the comparison performed in Figure 2, $2.5 \mathrm{mM}$ of $\mathrm{H}_{2} \mathrm{PtCl}_{6}$ in methanol or a mixture of 75 $\%$ water and $25 \%$ methanol (as indicated). The irradiation with the microwave reactor was maintained for 1 and 45 minutes, respectively, after the reaction mixtures turned dark brown (as indicated). The volume of the reaction mixture was $8 \mathrm{~mL}$.

For the comparison performed in Figure 3, $2.5 \mathrm{mM}$ of $\mathrm{H}_{2} \mathrm{PtCl}_{6}$ in mixture of methanol and water with different volume ratio (as indicated) was used. The irradiation with the microwave reactor was maintained for 45 minutes after the reaction mixtures turned dark. The volume of the reaction mixtures was 8 and $80 \mathrm{~mL}$, respectively, as indicated.

Synthesis of Pt NPs in alkaline ethylene glycol. The synthesis of NPs in ethylene glycol follows our previously reported recipe ${ }^{33}$ and is adapted to a micro-wave reactor synthesis ${ }^{34}$ : the solution containing $\mathrm{H}_{2} \mathrm{PtCl}_{6} \cdot 6 \mathrm{H}_{2} \mathrm{O}(20 \mathrm{mM})$ in alkaline ( $0.1 \mathrm{M}$ of base or higher as required, see Supporting Information) ethylene glycol is heated up with a microwave reactor (CEM Discover 
SP, $100 \mathrm{~W})$ in a dedicated flask $(35 \mathrm{~mL})$ until the temperature reaches $160{ }^{\circ} \mathrm{C}$ and maintained at this temperature for 3 minutes.

Re-dispersion studies. For re-dispersion studies, NPs that sediment after 24 hours from colloidal suspensions are separated from the supernatant by centrifugation at 2400 relative centrifugal forces for 5 minutes (4000 rotations per minute, Sigma 2-5) and re-dispersed in the desired solvent. The stability of the re-dispersion is followed over time and pictures taken at least on a weekly basis. A dispersion is considered stable if the supernatant maintained a brown or dark color and no significant agglomeration/sedimentation of NPs is observed at the bottom of the vials. Further stability tests are performed using centrifugation. The concentration of Pt NPs typically used for re-dispersion is determined by inductively coupled plasma mass spectrometry (ICP-MS) to vary between 0.1 and $0.5 \mathrm{~g} \mathrm{~L}^{-1}$.

Size distributions. The particle size distributions were evaluated by transmission electron microscopy (TEM). For TEM analysis a Jeol 2100 microscopes operated at $200 \mathrm{kV}$ was used. Size and morphology were estimated by recording images at three different magnification (at least $x 300000, x 400000, x 500000$ ) in 3 randomly selected areas of the grids (at least). The grids were prepared by dropping the solutions containing the NPs and low boiling point solvent (e.g. methanol and mixture with water) on a carbon coated copper grids (Quantifoil). The size and size distribution analysis were performed by measuring the size of at least 200 hundred (typically between 700 and 1000 NPs) using the ImageJ software.

Dynamic light scattering (DLS) was used as a complementary measurement technique allowing routine quality control. The analysis was carried out with a Litesizer 500 particle analyzer (Anton Paar) and the corresponding software Kalliope. The analysis parameters in the software were as follow; measurement: angle back scattering $175^{\circ}$; target temperature: $25^{\circ} \mathrm{C}$; 
equilibration time: 10 second; time for each run: 1 second; optical density filter: 2.0 ; focus position: $-3.5 \mathrm{~mm}$; material: platinum (refractive index: 2.4072, absorbance: 4.5083 ); solvent: methanol (refractive index: 1.3238, viscosity: $0.0005514 \mathrm{~Pa} \cdot \mathrm{s}$ ). The cuvettes used were disposables (Sarstedt) with a path length of $10 \mathrm{~mm}$. The particle suspensions (initial concentration of Pt: $2.5 \mathrm{mM}$ ) was diluted to a concentration of $0.0125 \mathrm{mM}(50 \mu \mathrm{L}$ Pt-NP suspension $+950 \mu \mathrm{L}$ methanol) resulting in a transmittance of $60 \%$. A series of 20 single runs was carried out for averaging.

Pt NP concentration. The amount of Pt in solutions was determined by inductively coupled plasma mass spectrometry (ICP-MS) as previously reported. ${ }^{35}$ Measurements were performed at The Max Planck Institute in Düsseldorf, Germany. The as-synthesized NPs where washed with 1 $\mathrm{M} \mathrm{HCl}$ before re-dispersion in ethylene glycol. For sample preparation an aliquot of the colloidal suspension (typically $100 \mu \mathrm{L}$ ) was digested in $4 \mathrm{~mL}$ of a mixture of $\mathrm{HCl}$ and $\mathrm{HNO}_{3}$ in a volume ratio $\mathrm{HCl}: \mathrm{HNO}_{3}$ (1:3) for 90 minutes on a hot plate at ca. $100{ }^{\circ} \mathrm{C}$. The volume was finally adjusted to $10 \mathrm{~mL}$ with Milli-Q water.

pH. The $\mathrm{pH}$ of solutions was measured using a $\mathrm{pH}$ meter (Symphony SP70P, VWR) with a glass electrode (InLab Routine, Mettler Toledo). $\mathrm{pH}$ of solutions was adjusted using $\mathrm{HCl}$ or $\mathrm{NaOH}$ solutions. Buffers were obtained mixing $\mathrm{NaHPO}_{4}$ and $\mathrm{Na}_{2} \mathrm{PO}_{4}$ (or $\mathrm{KHPO}_{4}$ and $\mathrm{K}_{2} \mathrm{PO}_{4}$ ) aqueous solutions at $10 \mathrm{mM}$ or $100 \mathrm{mM}$.

Zeta-potential measurements: Pt NPs $(100 \mu \mathrm{L}, 2.5 \mathrm{mM} \mathrm{Pt})$ were diluted to $1 \mathrm{~mL}$ with methanol and paced in a special designed quartz cuvette setup (Univette, Litesizer 500, Anton Paar) for analysis. The adjusted parameters in the acquisition and analysis software (Kalliope, Anton Paar) were equilibration time: $1 \mathrm{~min}$; approximation: Hueckel; temperature: $25^{\circ} \mathrm{C}$. The results reported were obtained with an average value of eight measurements for each sample. 
The background analysis (solvents without NPs) led to either a Zeta potential of $0 \mathrm{mV}$, or the acquisition did not return any value.

Head-space gas chromatography-mass spectrometry (GC-MS): a gas chromatograph Agilent 6890N Network GC System equipped with: a headspace sampler Agilent G1888 Network Headspace Sampler; a non-polar column Agilent 19091S-433 HP-5ms (5\%-phenyl) methyl poly siloxane $(30.0 \mathrm{~m}, 250 \mu \mathrm{m}, 0.25 \mu \mathrm{m})$; a mass spectrometer Agilent 5973 inert Mass Selective Detector were used. The chromatograms were acquired with a temperature ramp at $20{ }^{\circ} \mathrm{C} \min ^{-1}$ from 30 to $140{ }^{\circ} \mathrm{C}$.

\section{RESULTS AND DISCUSSION}

We first investigated the influence of the precursor on the Pt NP synthesis based on the optical appearance of the alkaline precursor solutions used for the synthesis. $\mathrm{H}_{2} \mathrm{PtCl}_{6}$ in alkaline $(\mathrm{NaOH})$ methanol is well established leading to well defined Pt NPs. ${ }^{27,}{ }^{28}$ The precursor solution is homogenous and dark-orange Figure $\mathbf{S 1}$ in supporting information, whereas $\mathrm{K}_{2} \mathrm{PtCl}_{6}$ in alkaline $(\mathrm{NaOH})$ methanol leads to yellowish solutions with partial dissolution of the complex and a pronounced turbidity, Figure S2. Performing the synthesis in alkaline $(\mathrm{NaOH})$ methanol with $\mathrm{K}_{2} \mathrm{PtCl}_{6}$ instead of $\mathrm{H}_{2} \mathrm{PtCl}_{6}$ does not lead to stable colloidal dispersions and large $\mathrm{Pt}$ agglomerates are observed after synthesis, Figure S2.

The detrimental influence of $\mathrm{K}^{+}$cations is also observed when adding $\mathrm{KCl}$ to a solution of $\mathrm{H}_{2} \mathrm{PtCl}_{6}$ prepared in alkaline $(\mathrm{NaOH})$ methanol. The solution without $\mathrm{K}^{+}$cations gives welldefined NPs but turns yellow and expresses the same turbidity as a solution prepared by $\mathrm{K}_{2} \mathrm{PtCl}_{6}$ precursor in methanol upon adding $\mathrm{KCl}$. This effect is not observed with $\mathrm{NaCl}$ and therefore can be addressed to the $\mathrm{K}^{+}$cation. $\mathrm{K}_{2} \mathrm{PtCl}_{4}$ is another $\mathrm{K}$-containing precursor that has been 
scrutinized, but it exhibits limited solubility in methanol and gets quickly reduced to large black agglomerates with or without presence of a base.

$\mathrm{K}$-containing reaction mixtures as well as $\mathrm{K}$-containing precursors therefore are challenging options to control the mono-alcohol synthesis of Pt NPs. A variety of Pt based complexes can form in methanol. ${ }^{36}$ These simple optical observations stress the possible role of cations in the stabilization of such complexes.

The rational selection of precursors and experimental conditions for NP synthesis therefore is a key to develop efficient syntheses of Pt NPs via the Co4Cat process. We systematically investigated the influence of monovalent alkali cations available from common bases to synthesize NPs with $\mathrm{H}_{2} \mathrm{PtCl}_{6}$ as precursor: $\mathrm{LiOH}, \mathrm{NaOH}, \mathrm{KOH}$ and $\mathrm{CsOH}$. It should be mentioned that $\mathrm{CsOH}$ is relatively expensive and not considered realistic for industrial applications. We use here $\mathrm{CsOH}$ only as an additional example to support the effect of monovalent cation in the synthesis of Pt NPs. An alkaline methanol solution of $\mathrm{H}_{2} \mathrm{PtCl}_{6}$ with $\mathrm{LiOH}$ changes color from yellow to dark brown upon thermal treatment; the same as when $\mathrm{NaOH}$ is used. This color change usually indicates the formation of Pt NPs. In comparison, with $\mathrm{KOH}$ or $\mathrm{CsOH}$ the solutions turn turbid and slowly become grey-dark over time or upon heat treatment, Figure S1.

Transmission electron microscopy (TEM) analysis, Figure 1, confirms that indeed Pt nanomaterials are obtained by using $\mathrm{LiOH}, \mathrm{NaOH}, \mathrm{KOH}$ or $\mathrm{CsOH}$, Figure S3, to prepare the alkaline methanol. The diameter of the NPs estimated by TEM when LiOH is used is (a) $1.8 \pm$ $0.5 \mathrm{~nm}$, in alkaline methanol and (b) $2.8 \pm 1.0 \mathrm{~nm}$ in an alkaline mixture of $75 \%$ water and $25 \%$ methanol; when $\mathrm{NaOH}$ is used the diameter is (c) $1.5 \pm 0.5 \mathrm{~nm}$ in alkaline methanol and, (d) 2.0 $\pm 0.6 \mathrm{~nm}$ in an alkaline mixture of $75 \%$ water and $25 \%$ methanol; when $\mathrm{KOH}$ (or $\mathrm{CsOH}$ ) is 
used large agglomerates are observed in both alkaline methanol and alkaline mixture of $75 \%$ water and $25 \%$ methanol. The nanoparticle size is confirmed to be in the range $1-2 \mathrm{~nm}$ by DLS measurements, Figure S4. These findings are consistent with the previously reported size increase with the water content using $\mathrm{NaOH} .{ }^{27,28}$

Before reaction, an alkaline $\mathrm{KOH}$ solution of $\mathrm{H}_{2} \mathrm{PtCl}_{6}$ in $75 \%$ water and $25 \%$ methanol does not turn turbid and is homogeneously orange, in contrast to a solution of $\mathrm{H}_{2} \mathrm{PtCl}_{6}$ in alkaline methanol. Nevertheless, in both cases, large agglomerates of several hundreds of nanometers are observed after synthesis, Figure 1e,f. Using $\mathrm{KOH}$, at low $\mathrm{H}_{2} \mathrm{PtCl}_{6}$ concentrations (e.g. $0.5 \mathrm{mM}$ ) and in alkaline mixture of water and methanol the formation of large agglomerates can be avoided, Figure S5. At this lower concentration of $\mathrm{H}_{2} \mathrm{PtCl}_{6}$ the size of the NPs is around $2 \mathrm{~nm}$ regardless of the amount of water used and the nature of the base, Figure S6.

Furthermore, although the as-synthesized colloidal dispersions are less stable using $\mathrm{KOH}$ or $\mathrm{CsOH}$ in alkaline mono-alcohols, these bases are perfectly suitable to obtain non-agglomerated Pt NPs if a support material is added during synthesis, Figure S7. However, these strategies are not considered satisfactory to tune the NP size and we here focus on the most stable colloidal NP dispersions.

In addition to size, the stability of as-synthesized colloidal suspensions is important to address in the context of achieving flexibility in the use of the NPs, e.g. for optimization of supported catalysts. $^{33}$ Thus it should be mentioned that also the solutions obtained using $\mathrm{NaOH}$ are not completely stable 27,28 and some NPs sediment within 24 hours after synthesis in both alkaline methanol and mixture with water. This can be better observed for syntheses with low $\mathrm{H}_{2} \mathrm{PtCl}_{6}$ concentration $(0.5 \mathrm{mM})$ or when the reaction is stopped just after the reaction mixture turns dark: e.g. Figure 2a where the reaction is stopped 1 minute after a dark brown color is observed. By 
comparison, if $\mathrm{LiOH}$ is used, this sedimentation is significantly less pronounced and overall more stable dispersions are obtained with this base. These results are in good agreement with Zeta potential that show the same trend as the cation hydration energy. We determined Zeta potentials of ca. $-65 \mathrm{mV}$ and $-57 \mathrm{mV}$ for colloids prepared with $\mathrm{Li}^{+}$and $\mathrm{Na}^{+}$, respectively, whereas for $\mathrm{K}^{+} 0 \mathrm{mV}$ were determined, Figure S8. In latter case no meaningful measurement was possible as the colloid quickly precipitates and one only probes the solvent.

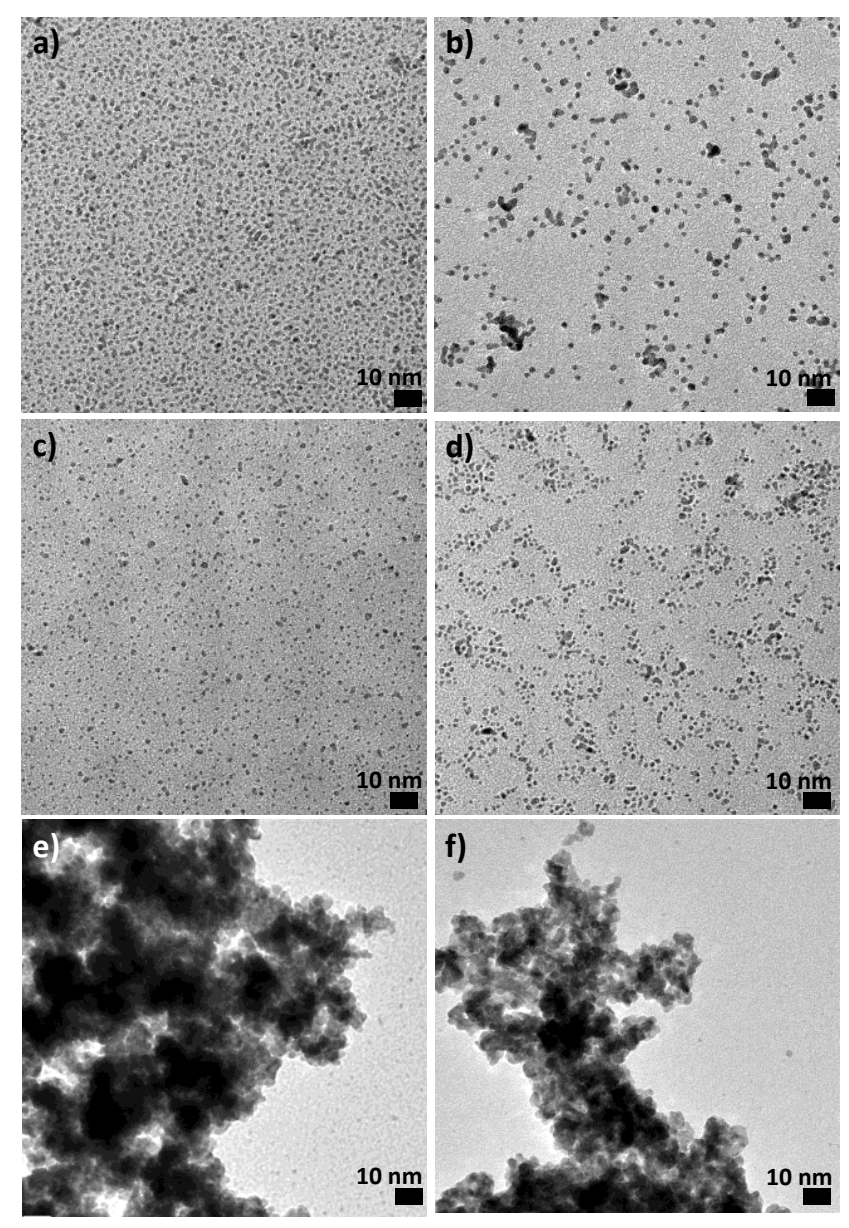

Figure 1. TEM micrographs of Pt NPs obtained using the mono-alcohol process using different bases: (a,b) $\mathrm{LiOH},(\mathrm{c}, \mathrm{d}) \mathrm{NaOH},(e, f) \mathrm{KOH}$ in $(\mathrm{a}, \mathrm{c}, \mathrm{e})$ alkaline methanol and $(\mathrm{b}, \mathrm{d}, \mathrm{f})$ an alkaline solution of $75 \%$ water in methanol. 


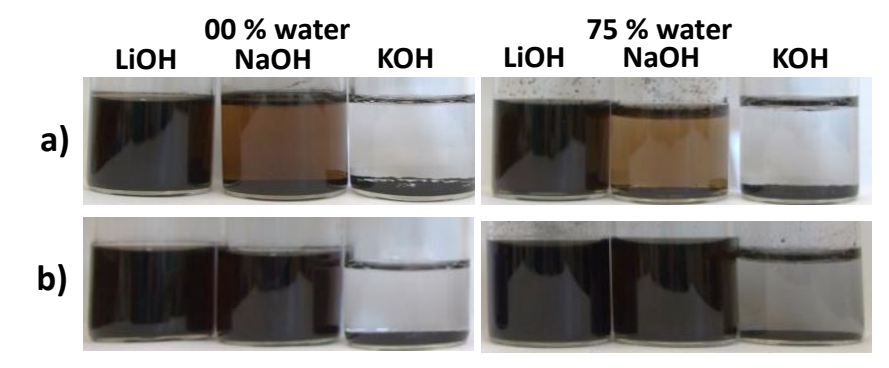

Figure 2. Images of as-synthesised colloidal suspensions of Pt NPs obtained by microwave irradiation at $100 \mathrm{~W}$ of an alkaline solution of $\mathrm{H}_{2} \mathrm{PtCl}_{6}(2.5 \mathrm{mM})$ in (left) methanol or (right) a mixture of methanol and $75 \%$ volume of water. The pictures were taken after (a) 5 days and (b) 5 months for a synthesis where the irradiation was maintained (b) 1 minutes and (b) 45 minutes after the solutions turned dark brown.

In summary, the stability of as prepared colloidal Pt NPs in alkaline methanol or alkaline methanol-water mixture decreases in the relative order $\mathrm{Li}^{+}>\mathrm{Na}^{+}>\mathrm{K}^{+} \approx \mathrm{Cs}^{+}$. This order corresponds to the decreasing hydration energy of the monovalent alkali cations. Such correlation has been previously observed in electrochemical experiments. ${ }^{30}$ Observed trends in the electrocatalytic activity of Pt in alkaline electrolyte were explained by the difference in hydration energy. It was claimed that the non-covalent interaction between hydrated alkali metal cations $\left(\mathrm{M}^{+}\left(\mathrm{H}_{2} \mathrm{O}\right)_{x}\right)$ and adsorbed $\mathrm{OH}\left(\mathrm{OH}_{\mathrm{ad}}\right)$ species on the Pt surface increases in the same order as the hydration energy of the respective cation, i.e. $\mathrm{Li}^{+}>>\mathrm{Na}^{+}>\mathrm{K}^{+}>\mathrm{Cs}^{+}$. The higher the hydration energy the higher the "concentration of $\mathrm{OH}_{\mathrm{ad}}-\mathrm{M}^{+}\left(\mathrm{H}_{2} \mathrm{O}\right)_{x}$ clusters at the interface". 30 
Our results could be interpreted based on the assumption that these clusters aid the stabilization of the colloidal suspension. In other words, in line with our previous work the NPs with $\mathrm{OH} / \mathrm{OH}^{-}$ species on their surfaces ${ }^{26,28}$ due to the alkaline synthesis medium are stabilized by alkali cations with increasing order of their hydration energy. An alternative explanation for the observed order in colloidal stability as function of the cation present in solution could be a cancellation of the negative surface charge by the respective cations. Such effect would affect the surface charge density and hence particle stability. For example, $\mathrm{Li}^{+}$is strongly hydrated and hence its charge is effectively screened by the hydration shell inhibiting its interaction and effective charge cancellation with the NP surface. By comparison, $\mathrm{K}^{+}$loses more easily its hydration shell allowing a stronger interaction with the adsorbed hydroxides thus inducing an electrostatic destabilization leading to a "collapse" in Zeta-potential.

Based on the available data, we cannot distinguish between these two models. Nevertheless, a clear correlation between the hydration enthalpy of the cation and the observed colloidal stability is demonstrated. In addition it cannot be excluded that oxidation products of methanol like formaldehyde ${ }^{29}$ or methyl formate formation (see Figure S9) contribute to the stabilization as well. Negatively charge species like formate could play a similar role to $\mathrm{OH}^{-}$. More likely their relatively simple further oxidation to $\mathrm{CO} / \mathrm{CO}_{2}$ contributes to the well documented stabilization of Pt NPs by CO groups adsorbed on the metal surface. ${ }^{25,26,28}$ In a similar way, the solvent purity may play a role in the stabilization of the NPs as organic solvents in general contain some degree of impurity. To scrutinize this effect, the synthesis was previously performed in four different research groups using chemicals from different grades and suppliers. ${ }^{27}$ No effect has been observed on the stability of the NPs. Possible impurities in the solvent may certainly influence 
the stabilization process but for the solvent grade used here and given the large excess of base used, the main stabilization mechanism is assigned to the nature of the cations.

Although not previously addressed, the effect of the cation would be expected in the welldocumented "surfactant-free" polyol synthesis. ${ }^{21}$ However, the use of a potassium based Pt precursor, $\mathrm{K}_{2} \mathrm{PtCl}_{6}$, has been previously reported in the surfactant-free polyol process without the mention of any major challenges. ${ }^{37}$ Testing the hypothesis further with $\mathrm{H}_{2} \mathrm{PtCl}_{6}$ and a typical base concentration, i.e. $0.2 \mathrm{M}$ of base in ethylene glycol, we observed no strong effect of the monovalent cation. In all cases stable colloidal suspensions are observed with a NP size around 2 $\mathrm{nm}$ regardless of the cation used. Only at high $\mathrm{KOH}$ concentration (e.g. $2.5 \mathrm{M}$ ) an effect of the cation could be observed: the starting reaction mixture turns turbid, Figure S10, as it is in the case in a mono-alcohol, Figure S1. We assume that the high viscosity of ethylene glycol partially compensates the poor stabilization expected for instance in presence of $\mathrm{K}^{+}$cations. The polyol synthesis is therefore less sensitive to cations than the Co4Cat synthesis, with the drawback of requiring a high boiling point solvent. This can explain why effects of cations were not investigated before.

The Co4Cat process enables to investigate the influence of subtle experimental parameters in the preparation of metals NP. Since LiOH is the most "robust" cation to achieve stable colloidal dispersion of Pt NPs by the Co4Cat process, a detailed study on the effect of the water content was performed. If LiOH is used, the size of the NPs increases with the water content, Figure 3, but instead of observing a significant increase in the mean value of the NP diameter as it is the case for $\mathrm{NaOH},{ }^{27,}{ }^{28}$ it is mainly the size dispersion that increases. Interestingly, with $\mathrm{LiOH}$, colloidal dispersions of Pt NPs with extremely high water content can be obtained. 
For instance, for a solution of $95 \%$ water and only $5 \%$ methanol, the resulting colloidal dispersion with a diameter of $2.5 \mathrm{~nm} \pm 1.3 \mathrm{~nm}$ are stable for at least 6 months. Conveniently this approach is scalable in volume from $8 \mathrm{~mL}$ to $80 \mathrm{~mL}$, Figure $3 \mathrm{G}$ and I. In contrast, with $\mathrm{NaOH}$, no stable solution could be obtained with water contents more than $87.5 \%$. In purely aqueous LiOH solution, however, the reduction of the Pt salt to Pt NPs is not observed and the reaction mixture remains yellow. This confirms that methanol plays the role of reducing agent in the synthesis. The $\mathrm{OH} / \mathrm{OH}$ - group formed on the surface of the NPs in alkaline conditions ${ }^{25}$ contribute to the stabilization of the NPs in a 'first stabilization shell'. It is shown here that the monovalent cations likely play the role of stabilizers in a 'second shell'.

Finally, re-dispersion of NPs is key to optimize processing in dedicated applications. Therefore, the influence of monovalent cations in the re-dispersion properties of the Pt NPs was studied as well. Since the NPs obtained with $\mathrm{LiOH}$ are stable as-synthesized, only re-dispersion properties of NPs obtained using $\mathrm{KOH}$ or $\mathrm{NaOH}$ are detailed here. It is found that NPs obtained using $\mathrm{KOH}$ do not re-disperse in aqueous solvents and not even in ethylene glycol or other solvents where NPs obtained by the polyol synthesis or Co4Cat synthesis using $\mathrm{NaOH}$ or $\mathrm{LiOH}$ would. Only in concentrated aqueous $\mathrm{NaOH}$ solution $(0.1 \mathrm{M})$ or $100 \mathrm{mM}$ sodium phosphate

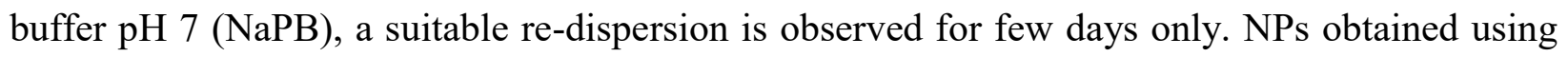
$\mathrm{KOH}$ re-disperse only in $\mathrm{Na}^{+}$-containing solutions: this is an additional evidence of the influence of the cations in the stabilization of the NPs obtained by the Co4Cat process. 

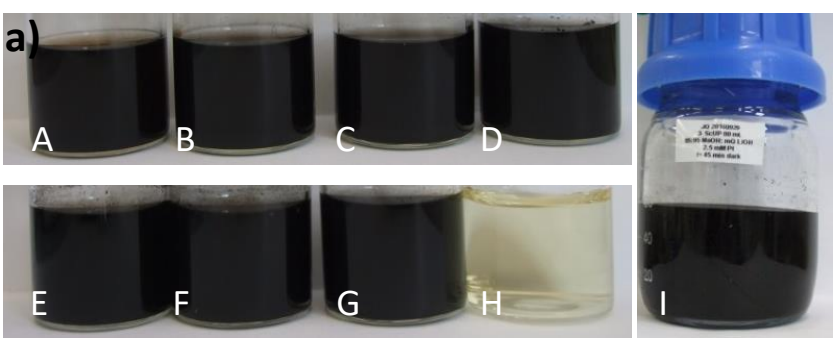

\begin{tabular}{ccccc}
\hline $\begin{array}{c}\text { b) } \\
\text { Sample }\end{array}$ & $\begin{array}{c}\text { Volume } \\
{[\mathrm{mL}]}\end{array}$ & $\% \mathrm{H}_{2} \mathrm{O}$ & $\begin{array}{c}\text { Diameter } \\
{[\mathrm{nm}]}\end{array}$ & $\begin{array}{c}\text { Standard } \\
\text { deviation } \\
{[\mathrm{nm}]}\end{array}$ \\
\hline $\mathrm{A}$ & 8 & 00 & 1.8 & 0.5 \\
$\mathrm{~B}$ & 8 & 25 & 2.3 & 0.7 \\
$\mathrm{C}$ & 8 & 50 & 2.3 & 0.7 \\
$\mathrm{D}$ & 8 & 65 & 2.6 & 1.0 \\
$\mathrm{E}$ & 8 & 75 & 2.8 & 1.0 \\
$\mathrm{~F}$ & 8 & 88 & 2.4 & 0.9 \\
$\mathrm{G}$ & 8 & 95 & 2.5 & 1.3 \\
$\mathrm{H}$ & 8 & 100 & - & - \\
I & 80 & 95 & 2.7 & 1.5 \\
\hline
\end{tabular}

Figure 3. (a) Pictures of as as-prepared colloidal suspension of Pt NPs in alkaline LiOH solutions of $\mathrm{H}_{2} \mathrm{PtCl}_{6}(2.5 \mathrm{mM}$, LiOH/Pt molar ratio of 20) in mixture of methanol and water. (b) Table gathering experimental parameters (volume of reaction mixture for synthesis and \% or water in volume) for the same samples. The diameter and the standard deviation are reported. The pictures were taken 5 months after the synthesis performed by thermal treatment at $100 \mathrm{~W}$ in a microwave, the reaction was irradiated for 45 minutes after the solutions turns dark under reflux conditions. TEM micrographs in Figure S11.

To control further the re-dispersion properties, the same batch of NPs prepared in alkaline $\mathrm{NaOH}$ methanol was used. The least stable $\mathrm{Pt} \mathrm{NPs}^{27,28}$ in the dispersion were collected by centrifugation 24 hours after synthesis and an equal amount of NPs was re-dispersed in equal 
volumes of aqueous solutions containing different cations: $\mathrm{NaCl}$ vs. $\mathrm{KCl}$; $\mathrm{NaOH}$ vs. $\mathrm{KOH}$ over a range of concentrations from $1 \mathrm{mM}$ to $1 \mathrm{M}$; but also 10 or $100 \mathrm{mM}$ buffers (sodium phosphate buffer, NaPB) vs. $\mathrm{K}_{2} \mathrm{PO}_{4} / \mathrm{KHPO}_{4}$ (potassium phosphate buffer, KPB), Figure 4. Phosphate ions are expected to stabilize Pt NPs due to an appropriate lattice size match ${ }^{8}$ but these buffers are also chosen to mimic biological media where Pt NPs could be used.

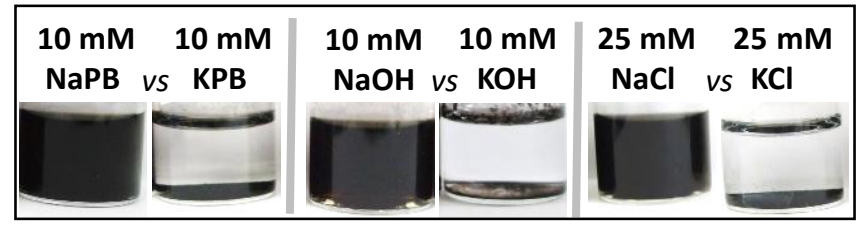

Figure 4. Pictures of Pt NPs obtained by the Co4Cat process using $\mathrm{NaOH}$ as base, re-dispersed in various solvents as indicated. Specifically, the influence of $\mathrm{Na}^{+}$is compared to that of $\mathrm{K}^{+}$for three different solvents.

In all cases the colloidal suspensions after re-dispersion are more stable in $\mathrm{Na}^{+}$-containing solvents compared to $\mathrm{K}^{+}$containing solvents, for equal concentrations and ionic strength. For Kcontaining media, the colloidal dispersions sediment after 24 hours. Only at lower $\mathrm{K}^{+}$ concentration (compared to a given $\mathrm{Na}^{+}$concentration) some relative stability is observed. For instance, NPs in $5 \mathrm{mM} \mathrm{KCl}$ are stable for months but only few days in $10 \mathrm{mM} \mathrm{KCl}$. At higher concentration, e.g. $1 \mathrm{M} \mathrm{NaOH}$ or $100 \mathrm{mM} \mathrm{NaPB}$, the NPs sediment within few days regardless of the cation used. The fact that a strong effect of the cation is observed not only in the synthesis but also the re-dispersion of 'unprotected' NPs obtained using $\mathrm{H}_{2} \mathrm{PtCl}_{6}$ as Pt source is inferred to the surface charge of the NPs: atomic cations most likely stabilize the NPs due to electrostatic interaction with $\mathrm{OH} / \mathrm{OH}^{-}$species on the $\mathrm{Pt}$ surface. ${ }^{30}$ The hydration energy of the cation 
decreases in the order $\mathrm{Li}^{+}>>\mathrm{Na}^{+}>\mathrm{K}^{+}>\mathrm{Cs}^{+}$. The stability of colloidal suspensions of the NPs follows the same trend.

In conclusion, the importance of the nature of the cation (precursor and base) in the Co4Cat surfactant-free process is addressed with regard to the synthesis, stabilization as well as redispersion of precious metal NPs. It is shown that simple and eco-friendly monovalent cations like $\mathrm{Li}^{+}$or $\mathrm{Na}^{+}$can be used as efficient stabilizers for colloidal dispersion of precious metal NPs. The work demonstrates that a deeper understanding of the intermediate species present during the formation of the NPs and detailed models to account for the stabilization of 'unprotected' NPs would be beneficial to control further the NP synthesis and processing.

\section{ASSOCIATED CONTENT}

Supporting Information. The following files are available free of charge. Pictures and TEM micrographs (PDF).

\section{AUTHOR INFORMATION}

\section{Corresponding Authors}

* jonathan.quinson@chem.ku.dk, matthias.arenz@dcb.unibe.ch

\section{ORCID}

Jonathan Quinson: 0000-0002-9374-9330 
Jan Bucher: N/A

Søren B. Simonsen: 0000-0001-7172-1225

Luise Theil Kuhn: 0000-0002-8403-1319

Sebastian Kunz: $\quad$ 0000-0002-2512-9316

Matthias Arenz: $\quad$ 0000-0001-9765-4315

\section{Conflict of interest}

The authors declared that the general synthesis method presented is subject to a patenting process (EP 3329990 A1, WO 2018/099958 A1).

\section{Present Addresses}

$\dagger$ Present address: Südzucker AG Central Department Research, Development, Services (CRDS) Wormser Straße 1167283 Obrigheim, Germany.

\section{Author Contributions}

The manuscript was written through contributions of all authors. All authors have given approval to the final version of the manuscript.

\section{ACKNOWLEDGEMENTS}

The authors acknowledge the support of the Villum Foundation in form of a block stipend. J.Q. received funding from the European Union's Horizon 2020 research and innovation programme under the Marie Skłodowska-Curie grant agreement No 703366 (SELECTRON). 


\section{REFERENCES}

1. Basri, S.; Kamarudin, S. K.; Daud, W. R. W.; Yaakub, Z. Nanocatalyst for direct methanol fuel cell (DMFC). Int. J. Hydrog. Energy 2010, 35, 7957-7970.

2. Kim, D.; Resasco, J.; Yu, Y.; Asiri, A. M.; Yang, P. D. Synergistic geometric and electronic effects for electrochemical reduction of carbon dioxide using gold-copper bimetallic nanoparticles. Nat. Commun. 2014, 5, Article ID 4948.

3. Davi, M.; Kessler, D.; Slabon, A. Electrochemical oxidation of methanol and ethanol on two-dimensional self-assembled palladium nanocrystal arrays. Thin Solid Films 2016, 615, 221225.

4. Wang, Y.; Zhang, J. L.; Wang, X. D.; Ren, J. W.; Zuo, B. J.; Tang, Y. Q. Metal nanoclusters stabilized with simple ions and solvents - promising building blocks for future catalysts. Top. Catal. 2005, 35, 35-41.

5. Rai, M.; Ingle, A. P.; Birla, S.; Yadav, A.; Dos Santos, C. A. Strategic role of selected noble metal nanoparticles in medicine. Crit. Rev. Microbiol. 2016, 42, 696-719.

6. Ozkar, S.; Finke, R. G. Nanocluster formation and stabilization fundamental studies: Ranking commonly employed anionic stabilizers via the development, then application, of five comparative criteria. J. Am. Chem. Soc. 2002, 124, 5796-5810.

7. Ozkar, S.; Finke, R. G. Transition-metal nanocluster stabilization fundamental studies: Hydrogen phosphate as a simple, effective, readily available, robust, and previously unappreciated stabilizer for well-formed, isolable, and redissolvable $\operatorname{Ir}(0)$ and other transitionmetal nanoclusters. Langmuir 2003, 19, 6247-6260. 
8. Finke, R. G.; Ozkar, S. Molecular insights for how preferred oxoanions bind to and stabilize transition-metal nanoclusters: a tridentate, C3 symmetry, lattice size-matching binding model. Coord. Chem. Rev. 2004, 248, 135-146.

9. Cookson, J. The Preparation of Palladium Nanoparticles. Platin. Met. Rev. 2012, 56, 8398.

10. Chen, C. W.; Tano, D.; Akashi, M. Colloidal platinum nanoparticles stabilized by vinyl polymers with amide side chains: Dispersion stability and catalytic activity in aqueous electrolyte solutions. J. Colloid Interface Sci. 2000, 225, 349-358.

11. Fievet, F.; Ammar-Merah, S.; Brayner, R.; Chau, F.; Giraud, M.; Mammeri, F.; Peron, J.; Piquemal, J.-Y.; Sicarda, L.; Viaub, G. The polyol process: a unique method for easy access to metal nanoparticles with tailored sizes, shapes and compositions. Chem. Soc. Rev. 2018, 47, 5187-5233.

12. Park, J. Y.; Aliaga, C.; Renzas, J. R.; Lee, H.; Somorjai, G. A. The Role of Organic Capping Layers of Platinum Nanoparticles in Catalytic Activity of CO Oxidation. Catal. Lett. 2009, 129, 1-6.

13. Naresh, N.; Wasim, F. G. S.; Ladewig, B. P.; Neergat, M. Removal of surfactant and capping agent from Pd nanocubes (Pd-NCs) using tert-butylamine: its effect on electrochemical characteristics. J. Mater. Chem. A 2013, 1, 8553-8559.

14. Liu, W.; Wang, H. L. Influence of surface capping on oxygen reduction catalysis: A case study of 1.7 nm Pt nanoparticles. Surf. Sci. 2016, 648, 120-125.

15. Cargnello, M.; Chen, C.; Diroll, B. T.; Doan-Nguyen, V. V. T.; Gorte, R. J.; Murray, C. B. Efficient Removal of Organic Ligands from Supported Nanocrystals by Fast Thermal 
Annealing Enables Catalytic Studies on Well-Defined Active Phases. J. Am. Chem. Soc. 2015, 137, 6906-6911.

16. Duan, H. H.; Wang, D. S.; Li, Y. D. Green chemistry for nanoparticle synthesis. Chem. Soc. Rev. 2015, 44, 5778-5792.

17. Olveira, S.; Forster, S. P.; Seeger, S. Nanocatalysis: Academic Discipline and Industrial Realities. J. Nanotech. 2014, Article ID 324089. DOI: 10.1155/2014/324089.

18. Kawasaki, H. Surfactant-free solution-based synthesis of metallic nanoparticles toward efficient use of the nanoparticles' surfaces and their application in catalysis and chemo/biosensing. Nanotechnol. Rev. 2013, 2, 5-25.

19. Zhang, D. S.; Goekce, B.; Barcikowski, S. Laser Synthesis and Processing of Colloids: Fundamentals and Applications. Chem. Rev. 2017, 117, 990-4103.

20. Rehbock, C.; Merk, V.; Gamrad, L.; Streubel, R.; Barcikowski, S. Size control of laserfabricated surfactant-free gold nanoparticles with highly diluted electrolytes and their subsequent bioconjugation. Phys. Chem. Chem. Phys. 2013, 15, 3057-3067.

21. Wang, Y.; Ren, J. W.; Deng, K.; Gui, L. L.; Tang, Y. Q. Preparation of tractable platinum, rhodium, and ruthenium nanoclusters with small particle size in organic media. Chem. Mater. 2000, 12, 1622-1627.

22. Dong, H.; Chen, Y. C.; Feldmann, C. Polyol synthesis of nanoparticles: status and options regarding metals, oxides, chalcogenides, and non-metal elements. Green Chem. 2015, $17,4107-4132$.

23. Quinson, J.; Inaba, M.; Neumann, S.; Swane, A.; Bucher, J.; Simonsen, S.; Theil Kuhn, L.; Kirkensgaard, J.; Jensen, K.; Oezaslan, M.; Kunz, S.; Arenz, M. Investigating Particle Size Effects in Catalysis by Applying a Size-Controlled and Surfactant-Free Synthesis of Colloidal 
Nanoparticles in Alkaline Ethylene Glycol: Case Study of the Oxygen Reduction Reaction on Pt ACS Catal. 2018, 8, 6627-6635.

24. Zheng, Y. Y.; Dou, Z. J.; Fang, Y. X.; Li, M. W.; Wu, X.; Zeng, J. H.; Hou, Z. H.; Liao, S. J. Platinum nanoparticles on carbon-nanotube support prepared by room-temperature reduction with $\mathrm{H}-2$ in ethylene glycol/water mixed solvent as catalysts for polymer electrolyte membrane fuel cells. J. Power Sources 2016, 306, 448-453.

25. Schrader, I.; Warneke, J.; Neumann, S.; Grotheer, S.; Swane, A. A.; Kirkensgaard, J. J. K.; Arenz, M.; Kunz, S. Surface Chemistry of "Unprotected" Nanoparticles: A Spectroscopic Investigation on Colloidal Particles. J. Phys. Chem. C 2015, 119, 17655-17661.

26. Neumann, S.; Grotheer, S.; Tielke, J.; Schrader, I.; Quinson, J.; Zana, A.; Oezaslan, M.; Arenz, M.; Kunz, S. Nanoparticles in a box: a concept to isolate, store and re-use colloidal surfactant-free precious metal nanoparticles. J. Mater. Chem. A 2017, 5, 6140-6145.

27. Quinson, J.; Neumann, S.; Wannmacher, T.; Kacenauskaite, L.; Inaba, M.; Bucher, J.; Bizzotto, F.; Simonsen, S. B.; Kuhn, L. T.; Bujak, D.; Zana, A.; Arenz, M.; Kunz, S. Colloids for Catalysts: A concept for the preparation of superior catalysts of industrial relevance. Angew. Chem. Int. Ed. 2018, 57, 12338-12341.

28. Quinson, J.; Kacenauskaite, L.; Bucher, J.; Simonsen, S. B.; Kuhn, L. T.; Oezaslan, M.; Kunz, S.; Arenz, M. Controlled synthesis of surfactant-free water-dispersible colloidal platinum nanoparticles by the Co4Cat process. ChemSusChem 2019, 12, 1229-1239.

29. Wojnicki, M.; Kwolek, P. Reduction of hexachloroplatinate(IV) ions with methanol under UV radiation. J. Photochem. Photobiol. A 2016, 314, 133-142. 
30. Strmcnik, D.; Kodama, K.; van der Vliet, D.; Greeley, J.; Stamenkovic, V. R.; Markovic, N. M. The role of non-covalent interactions in electrocatalytic fuel-cell reactions on platinum. Nat. Chem. 2009, 1, 466-472.

31. Prat, D.; Wells, A.; Hayler, J.; Sneddon, H.; McElroy, C. R.; Abou-Shehada, S.; Dunn, P. J. CHEM21 selection guide of classical- and less classical-solvents. Green Chem. 2016, 18, 288296.

32. Yang, J.; Deivaraj, T. C.; Too, H. P.; Lee, J. Y., Acetate stabilization of metal nanoparticles and its role in the preparation of metal nanoparticles in ethylene glycol. Langmuir 2004, 20, 4241-4245.

33. Speder, J.; Altmann, L.; Roefzaad, M.; Baumer, M.; Kirkensgaard, J. J. K.; Mortensen, K.; Arenz, M. Pt based PEMFC catalysts prepared from colloidal particle suspensions - a toolbox for model studies. Phys. Chem. Chem. Phys. 2013, 15, 3602-3608.

34. Inaba, M.; Quinson, J.; Arenz, M. pH matters: The influence of the catalyst ink on the oxygen reduction activity determined in thin film rotating disk electrode measurements. J. Power Sources 2017, 353, 19-27.

35. Speder, J.; Zana, A.; Spanos, I.; Kirkensgaard, J. J. K.; Mortensen, K.; Hanzlik, M.; Arenz, M. Comparative degradation study of carbon supported proton exchange membrane fuel cell electrocatalysts - The influence of the platinum to carbon ratio on the degradation rate. $J$. Power Sources 2014, 261, 14-22.

36. Chen, S. M.; Yang, Q. Y.; Wang, H. H.; Zhang, S.; Li, J.; Wang, Y.; Chu, W. S.; Ye, Q.; Song, L. Initial Reaction Mechanism of Platinum Nanoparticle in Methanol-Water System and the Anomalous Catalytic Effect of Water. Nano Lett. 2015, 15, 5961-5968. 
37. Boita, J.; Nicolao, L.; Alves, M. C. M.; Morais, J. Observing Pt nanoparticle formation at the atomic level during polyol synthesis. Phys. Chem. Chem. Phys. 2014, 16, 17640-17647.

\section{SYNOPSIS}

Alkali cations are simple and eco-friendly stabilizers for surfactant-free precious metal nanoparticles with the decreasing order of efficiency: $\mathrm{Li}^{+}>\mathrm{Na}^{+}>\mathrm{K}^{+} \approx \mathrm{Cs}^{+}$.

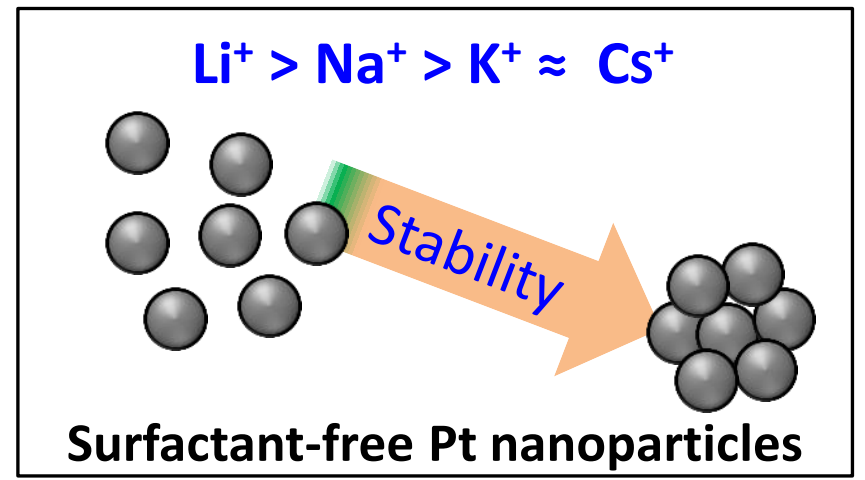

